\title{
COREDEs Missões e Litoral: duas realidades e uma perspectiva sob a égide da política de crédito rural
}

Jaqueline Mallmann Haas*

\begin{abstract}
Resumo
Historicamente as Políticas Públicas Brasileiras, voltadas ao meio rural, tinham por finalidade aumento da produção e produtividade, tendo o crédito rural papel de destaque. Neste sentido, o estudo objetiva analisar a captação de recursos e contratos do PRONAF por dois distintos Coredes do Rio Grande do Sul: Missões e Litoral, em um intervalo de 06 anos. Para tanto, a metodologia da pesquisa constitui-se, além de revisão bibliográfica, na coleta de dados secundários extraídos da Matriz de Dados do Crédito Rural (MDCR) do Banco Central do Brasil. Os resultados demonstram a existência de uma concentração dos recursos nas mãos de um grupo cada vez menor de agricultores e municípios em ambos os Coredes. Percebe-se uma tendência de que o PRONAF está a beneficiar agricultores já consolidados, na maioria das vezes pautados na especialização produtiva, enquanto os agricultores em situação de vulnerabilidade encontram maiores dificuldades de modificar sua realidade.
\end{abstract}

Palavras-chave: COREDE; PRONAF; Política Pública, Desenvolvimento Rural.

\section{Coredes Missões and Litoral: two realities and a perspective under the age of rural credit policy}

\begin{abstract}
Historically, the Brazilian Public Policies, aimed at the rural environment, aimed at increasing production and productivity, with rural credit having a prominent role. In this sense, the study aims to analyze the funding of PRONAF resources and contracts by two distinct Coredes of Rio Grande do Sul: Missões and Litoral, in a range of 06 years. To do so, the research methodology constitutes, besides a bibliographical review, the collection of secondary data extracted from the Rural Credit Data Matrix (MDCR) of the Central Bank of Brazil. The results demonstrate the existence of a concentration of resources in the hands of a smaller group of farmers and municipalities in both Coredes. There is a tendency for PRONAF to benefit already established farmers, most of whom are based on specialization in production, while farmers in situations of vulnerability find it more difficult to change their reality
\end{abstract}

Key words: COREDE; PRONAF; Public Policy, Rural Development.

\section{Introdução}

Este trabalho procura contribuir com a discussão sobre a capacidade de políticas públicas, no caso específico do crédito rural subsidiado, de auxiliar na transformação de realidades, especialmente de regiões mais empobrecidas, tomando por base dois Coredes localizados no estado do Rio Grande do Sul, em um intervalo de 6 anos, a saber 2013-2018.

Historicamente as Políticas Públicas Brasileiras, voltadas ao meio rural, tinham por finalidade única o aumento da produção e produtividade. No âmbito das políticas públicas setoriais, o crédito rural, tem papel de destaque nas transformações da agropecuária brasileira, e atualmente o Brasil conta com dois instrumentos: o Sistema Nacional de Crédito Rural (SNCR)

* Doutorado em Extensão Rural (UFSM). Professora do Programa de Pós-Graduação em Dinâmicas Regionais e Desenvolvimento (PGDREDES) da Universidade Federal do Rio Grande do Sul, Campus Litoral Norte (UFRGS). http://orcid.org/0000-0001-9742-7761 E-mail: haasjaqueline@gmail.com 
e o Programa Nacional de Fortalecimento da Agricultura Familiar (PRONAF), que por sua vez, são as principais políticas agrícolas em termos de recursos financeiros aplicados na agricultura brasileira.

O PRONAF, objeto de análise deste estudo, surge no sentido de transformar a realidade da Agricultura Familiar no país, e ao longo de sua trajetória o programa foi sendo reestruturado a fim de ampliar seu público beneficiário e a diversificação nas suas linhas de crédito (AQUINO; SCHNEIDER, 2015). O Programa Nacional de Fortalecimento da Agricultura Familiar (PRONAF), passados mais de vinte anos desde sua criação, apresenta-se como uma política pública de muita relevância dentro do território brasileiro, como vem sendo apontado por inúmeros pesquisadores da área no decorrer destas duas décadas. Direcionado a um categoria social com grande importância sociocultural e econômica, a qual historicamente é sinônimo de resistência frente aos desafios impostos, o PRONAF além de possibilitar melhoria na qualidade de vida das(os) agricultoras(os) que fazem o acesso à política, contribuí para a melhora dos indicadores de segurança alimentar do país, entregando qualidade e diversidade de alimentos às mesas dos brasileiros e integrando uma parte das(os) Agricultoras(es) Familiares ao planejamento econômico do Brasil (GRISA, WESZ JR. e BUCHWEITZ, 2014). Nesse sentido, se justificam os estudos direcionados a entender os fatores sociais, culturais e econômicos que esta política pública promove, sendo este o intuito também do presente trabalho.

O objetivo geral deste estudo é examinar, de forma conjunta, os resultados de duas regiões distintas do estado do Rio Grande do Sul, qual seja, COREDE Missões e COREDE Litoral, sobre o acesso a uma das principais políticas públicas de apoio à agricultura familiar, o PRONAF, tomando por base fundamentalmente o número de acessos e valores acessados no intervalo dos anos de 2013 e 2018.

As regiões analisadas no trabalho são respectivamente o COREDE Litoral, composto por 21 municípios $^{1}$, bem como a região compreendida pelo Conselho Regional de Desenvolvimento Missões (COREDE - Missões), abrangendo 25 municípios². A escolha das regiões, evidenciou Coredes com menor participação na composição do PIB do estado do Rio Grande do Sul (entre

\footnotetext{
${ }^{1}$ Arroio do Sal, Balneário Pinhal, Capão da Canoa, Capivari do Sul, Caraá, Cidreira, Dom Pedro de Alcântara, Imbé, Itati, Mampituba, Maquiné, Morrinhos do Sul, Mostardas, Osório, Palmares do Sul, Terra de Areia, Torres, Tramandaí, Três Cachoeiras, Três Forquilhas e Xangri-lá;

${ }^{2}$ Bossoroca, Caibaté, Cerro Largo, Dezesseis de Novembro, Entreljuís, Eugênio de Castro, Garruchos, Giruá, Guarani das Missões, Mato Queimado, Pirapó, Porto Xavier, Rolador, Roque Gonzales, Salvador das Missões, Santo Ângelo, Santo Antônio das Missões, São Luiz Gonzaga, São Miguel das Missões, São Nicolau, São Paulo das Missões, São Pedro do Butiá, Sete de Setembro, Ubiretama e Vitória das Missões.
} 
0,68\% e 2\%), no ano de 2015, bem como, realidades bastante dispares e distantes geograficamente uma da outra (FEE, 2019).

O estudo foi realizado a partir da revisão bibliográfica de parte da produção acadêmica disponível sobre o tema e utilizou como dados quantitativos informações obtidas junto ao banco de dados do Banco Central do Brasil, referentes ao total de contratos e valores acessados para atividades agrícola e pecuária, para as finalidades de custeio, investimento, comercialização e industrialização, no intervalo dos anos de 2013 e 2018. Destaca-se que a escolha dos anos, seguiu a disponibilidade dos dados para acesso.

Por fim, o presente trabalho está dividido em cinco sessões, sendo esta sessão introdutória a primeira delas, na qual apresenta-se a contextualização, objetivo da pesquisa e metodologia empregada para a realização do trabalho. Na sequência realiza-se uma rápida discussão sobre o histórico das políticas públicas no Brasil, seguida por um debate mais específico referente ao PRONAF (sessão 2). Na terceira seção apresenta-se as especificidades dos Coredes Missões e Litoral, bem como dados referentes ao número de contratos e recursos captados no intervalo dos anos de 2013 e 2018, e, por fim, apresenta-se as considerações finais do estudo (sessão 4).

\section{Políticas públicas}

Até meados da década de 1990, o processo político de formulação e execução das políticas públicas voltadas para o meio rural, em especial para a agricultura familiar, apresentavam um determinado formato. Posteriormente transformado, consolidou-se em um novo formato, possibilitando o surgimento de novas ideias, novas ações, novos programas e novas políticas.

Diversos programas e políticas públicas foram então, no decorrer dos últimos anos, constituídos e disponibilizados para a categoria social da agricultura familiar brasileira. Entre essas ações implementadas pelo Estado para a agricultura familiar, está o Programa Nacional de Fortalecimento da Agricultura Familiar (PRONAF), criado em 1995 pelo governo federal com o objetivo de prestar um atendimento diferenciado aos agricultores familiares, cuja produção é resultado da própria força de trabalho, segundo Anjos et al (2004).

A literatura recente sobre políticas públicas no meio rural brasileiro vem demonstrando com evidências cada vez mais consistentes que as interfaces entre atores e Estado constituem 
uma nova forma de agir do Estado brasileiro, bem como das organizações sociais rurais (BOLTER, 2013).

O Brasil passou por diferentes períodos no que diz respeito ao processo político de formulação das políticas públicas voltadas para o meio rural. Nos anos que antecedem a redemocratização, segundo Lamounier (1994), constatava-se pouca participação social, devido às restrições impostas pelo regime autoritário, bem como à feição distributiva das políticas agrícolas (BOLTER, 2013).

As políticas públicas direcionadas para o meio rural (período conhecido como a Modernização Agrícola) eram implementadas de forma top-down e dirigidas pelo Estado (que define as políticas e as implementa), tendo um viés econômico/produtivo. Especificamente em 1965, no país se instituiu um Sistema Nacional de Crédito Rural (SNCR), obrigando a rede bancária púbica e privada a direcionar um porcentual de seus recursos para créditos rurais de custeio, comercialização e investimento com taxas de juros bastante subsidiadas (menores que as correntes no mercado e, muitas vezes, abaixo da taxa de inflação) (CARNEIRO, 1997)

Após a redemocratização, o processo político de formulação das políticas públicas passou a ter um viés mais participativo. No período pós-redemocratização, as organizações sindicais rurais brasileiras passaram a atuar em ações antes centradas no Estado, que se tornou mais permeável e mais receptivo às questões/propostas oriundas da sociedade civil organizada. Com isso, após a Constituição de 1988, o cotidiano dessas organizações se alterou significativamente: a atuação deixou de estar centrada nos movimentos "combativos" e foi ampliada para os movimentos "propositivos". Tal período se refere ao momento em que as políticas públicas começaram a ser coformuladas (BOLTER, 2013).

Ao longo dos anos de 1990, segundo Grisa (2012), novas ideias, oriundas da participação de novos atores sociais, passaram a ser analisadas e instituídas. O Estado, que até então atuava de forma isolada no processo, tornou-se mais permeável, levando à que o processo político de formulação das políticas públicas se alterasse significativamente em todos os níveis.

Em suma, percebe-se que o processo de formulação das políticas públicas voltadas para o meio rural se alterou significativamente ao longo dos últimos anos. Nas décadas de 1960 e 1970, as políticas públicas direcionadas para o meio rural foram implementadas de "cima para baixo" e dirigidas pelo Estado. Nesse período, verifica-se a ocorrência, por um lado, de um processo de modernização da agricultura via modernização das estruturas produtivas, e, por outro, de um processo de concentração de renda e de terra que acentuou a desigualdade social 
e provocou sérios problemas econômicos e ambientais no espaço rural (GRAZIANO DA SILVA, 1998).

Em meados da década de 1980, as políticas públicas voltadas para o meio rural passaram a ser instituídas, mesmo que ainda dirigidas pelo Estado, com um viés setorial. O Estado começou a dialogar com determinados setores da sociedade, visando organizar os sistemas de produção, comercialização e industrialização da produção rural brasileira. Porém, esse processo centrou-se no "cume" empresarial produtivo (TAKAGI, 2004).

Um terceiro momento, registrado após 1993 (período destacado como o retorno do processo institucional democrático e pós-estabilização econômica do país, em que diversas determinações da Constituição de 1988 entraram em vigor), legitimou um novo processo de formulação de ações, programas e políticas públicas voltadas para o meio rural. As ações estatais direcionadas para esse meio passaram a ser coformuladas, coproduzidas e cogestadas pelos diversos atores sociais que atuavam no processo político e institucional. Nesse período, passaram a ser instituídas ações, políticas e programas de valorização da pequena e da média produção rural, além da valorização social e cultural (MÜLLER, 2007; ASSIS, 2007).

\subsection{Política de crédito rural}

O crédito rural foi criado no País em 1935. Durante 30 anos, sua gestão coube ao Banco do Brasil, por meio da Carteira de Crédito Agrícola e Industrial, tornando o crédito rural mais acessível aos pequenos produtores. Em 1965, o assunto passou a ser responsabilidade do Banco Central, com a implementação do Sistema Nacional de Crédito Rural (SNCR), sendo o mesmo sistematizado pela Lei no 4.829/65 e disciplinado pelo Decreto $n=58.380 / 66$, estando restrito ao campo específico do financiamento das atividades rurais. O período após a criação do SNCR foi de grande expansão no crédito rural brasileiro, motivada, principalmente, pela grande liquidez econômica mundial. Através do SNCR, fomentou-se as condições para que os agricultores adquirissem os meios necessários para dinamizar a produção (insumos, máquinas e equipamentos, etc.), no entanto, ele também foi altamente seletivo, levando a um processo de modernização desigual, com privilégios diferenciados a produtores, produtos e regiões. 0 crédito rural e os subsídios a ele vinculado privilegiaram, sobretudo, os grandes proprietários, em detrimento dos pequenos produtores. 
Com a crise internacional do petróleo no final dos anos 1970 e o aumento das taxas de inflação no Brasil, a política agrícola deixa de ser prioritária. Passando o sistema de crédito rural a ser muito criticado no início dos anos 1980. Os principais críticos argumentavam que seus efeitos eram poucos significativos sobre o crescimento da produção agrícola, sobre as tecnologias empregadas pelos produtores rurais e sobre a elevação dos níveis de produtividade (GIMENES; GIMENES; GOZER, 2008).

Com o Estado enfrentando uma crise financeira nos anos 1980, a consequência foi o esgotamento da capacidade de financiamento do Sistema Nacional de Crédito Rural, e a consequente queda do valor dos financiamentos concedidos por este Sistema. Portanto, em 1984, os subsídios ao crédito foram eliminados. Segundo Pretto (2005), tais mudanças no padrão de financiamento, tornaram o acesso dos pequenos agricultores, ao crédito, ainda mais difícil, durante este período.

Surge então na década de 1990, mais precisamente 1995, o PRONAF, buscando diminuir as dificuldades relacionadas ao elevado custo e a escassez de crédito enfrentados pelos agricultores, em particular os pequenos/familiares.

\subsubsection{Um rápido retrospecto do PRONAF}

Para o segmento da agricultura familiar a criação do Programa Nacional de Fortalecimento da Agricultura Familiar (PRONAF) é "um novo marco histórico na intervenção do Estado na agricultura Brasileira" (GAZOLLA, 2004, p. 154). Em termos político-institucionais a agricultura familiar alcança legitimidade a partir da criação do Programa Nacional de Fortalecimento da Agricultura Familiar, que surgiu na segunda metade da década de 1990, com a intenção de fortalecer as atividades dos pequenos agricultores familiares, por meio da disponibilização de crédito rural com baixas taxas de juros, além de apoio técnico qualificado. Trata-se de uma política pública, direcionada a um seguimento da sociedade que até então era excluído dos planejamentos, tanto no âmbito agrícola do país, quanto à possibilidades de melhorias na qualidade de vida. Com o financiamento das atividades econômicas, o programa influencia diretamente na vida das famílias de agricultores familiares, fortalecendo a vida do campo, ou seja a permanência da(o) agricultora(o) no campo, contribuindo assim para a diminuição do êxodo rural, o que por sua vez mantêm a qualidade e diversidade de alimentos para os brasileiros e inclui mesmo que ainda pequena, uma parte dos produtores rurais que 
estavam e em certa medida ainda estão, excluídos dos planejamentos econômicos do estado Brasileiro (GAZOLLA, 2004).

Especificamente, em 1994 surgiu o PROVAP (Programa de Valorização da Pequena Produção Rural), primeiro programa pensado a dar maior condições econômicas e consequentemente de melhorias na qualidade de vida dos pequenos produtores, por meio da criação de linhas de crédito com taxas mais baixas que as praticadas tradicionalmente pelo mercado. Um ano mais tarde, através da reformulação do PROVAP, nasceu o PRONAF (Programa Nacional de Fortalecimento da Agricultura Familiar), que entrou em vigência através do decreto no 1.946, de 28 de junho de 1996, conforme Anjos et al (2004).

O PRONAF concede crédito para investimento ou custeio de atividades econômicas rurais de pequenos agricultores e assentados da reforma agrária, com baixas taxas de juros, com o intuito de promover a melhoria da vida das famílias de pequenos agricultores, contribuindo dentre outros, para a existência da vida no campo e para a segurança alimentar brasileira, uma vez que $70 \%$ dos alimentos que chegam até a mesa da população no Brasil são provenientes da Agricultura Familiar.

Para o agricultor familiar acessar e se encaixar em alguma das Linhas de Créditos existentes dentro do programa, inicialmente ele deve obter uma Declaração de Aptidão ao PRONAF (DAP), a qual pode ser solicitada junto às empresas de assistência técnica e extensão rural (Ater), sendo que a mesma será baseada na renda anual da exploração e produção da família na propriedade familiar rural. Atualmente o PRONAF disponibiliza 12 linhas de créditos: PRONAF Custeio, PRONAF Mais Alimentos, PRONAF Agroindústria, PRONAF Agroecologia, PRONAF Eco, PRONAF Floresta, PRONAF Semiárido, PRONAF Mulher, PRONAF Jovem, PRONAF Custeio e Comercialização de Agroindústrias Familiares, PRONAF Cota-Parte e Microcrédito Rural (Brasil, 2018). O PRONAF financia projetos individuais ou coletivos, com taxas de juros reduzidas, que gerem renda a agricultores familiares assentados da reforma agrária e a povos e a comunidades tradicionais. Financia a execução de atividades agropecuárias, compra de equipamentos e contribui para o aumento da renda e melhoria da qualidade de vida no campo.

Destaca-se que os modelos de política pública são muito importantes para o desenvolvimento regional, pois podem ou não favorecer o bem-estar da sociedade. Para isso, torna-se essencial a máxima participação na formulação, implementação e avaliação das políticas públicas, principalmente, buscando uma articulação dos atores sociais e dos atores gestores da política pública. 
3 Coredes Missões e Litoral: analisando dois contextos sob a influência de uma política de crédito

A cultura de planejamento do território no caso do Rio Grande do Sul, embora tenha suas primeiras iniciativas com estudos enfocando a Metade Sul, desenvolvem-se com maior corpo pela estruturação dos Conselhos Regionais de Desenvolvimento (Coredes) na década de 1990, pautadas nos experimentos de regionalização de outras regiões, onde se formalizaram pelo estabelecimento de vinte e oito (28) conselhos regionais (WBATUBA et al., 2017).

O histórico dos Conselhos Regionais de Desenvolvimento inicia-se quando de sua instituição em junho de 1992 e formalização em 1994, pelo Decreto no 35.764 de 28/12/1994. Os Conselhos constituem-se fundamentalmente, em fóruns de discussão e decisão a respeito de políticas e ações que visem o desenvolvimento regional. Tendo por objetivos assim a promoção do desenvolvimento regional, harmônico e sustentável, a integração dos recursos e das ações do governo na região, a melhoria da qualidade de vida da população, a distribuição equitativa da riqueza produzida, o estímulo à permanência do homem em sua região e a preservação e recuperação do meio ambiente. Os Coredes são frutos de uma divisão administrativa e política do Estado do Rio Grande do Sul (SECRETARIA DE..., 2020), conforme pode ser visto na Figura 1.

O COREDE Missões, especificamente, localiza-se na região Noroeste do estado do Rio Grande do Sul e sua área total corresponde a 4,6\% do território do Estado, ao passo que o COREDE Litoral se localiza na região do Litoral Norte Gaúcho, com área correspondente a 2,5\% da área total do Estado. Outros indicadores dos mesmos, podem ser visualizados na Tabela 1.

Tabela 1 - Indicadores dos Coredes em estudo

\begin{tabular}{lrr}
\hline Indicadores dos Coredes Missões e Litoral & Missões & Litoral \\
\hline População Total (Mil habitantes, estimativa 2017) & 250.041 & 342.431 \\
Área Total (Km², 2015) & $12.855,53$ & $7.115,79$ \\
Taxa de analfabetismo (\%, 2010) & 12,43 & 10,22 \\
Expectativa de Vida (anos, 2000) & 72,08 & 73,34 \\
PIB per capita (R\$̦, 2013) & $25.232,41$ & $18.826,16$ \\
\hline
\end{tabular}

Fonte: FEE (2019) 
Figura 1 - Mapa dos Coredes com destaque para a localização dos Coredes Missões e Litoral

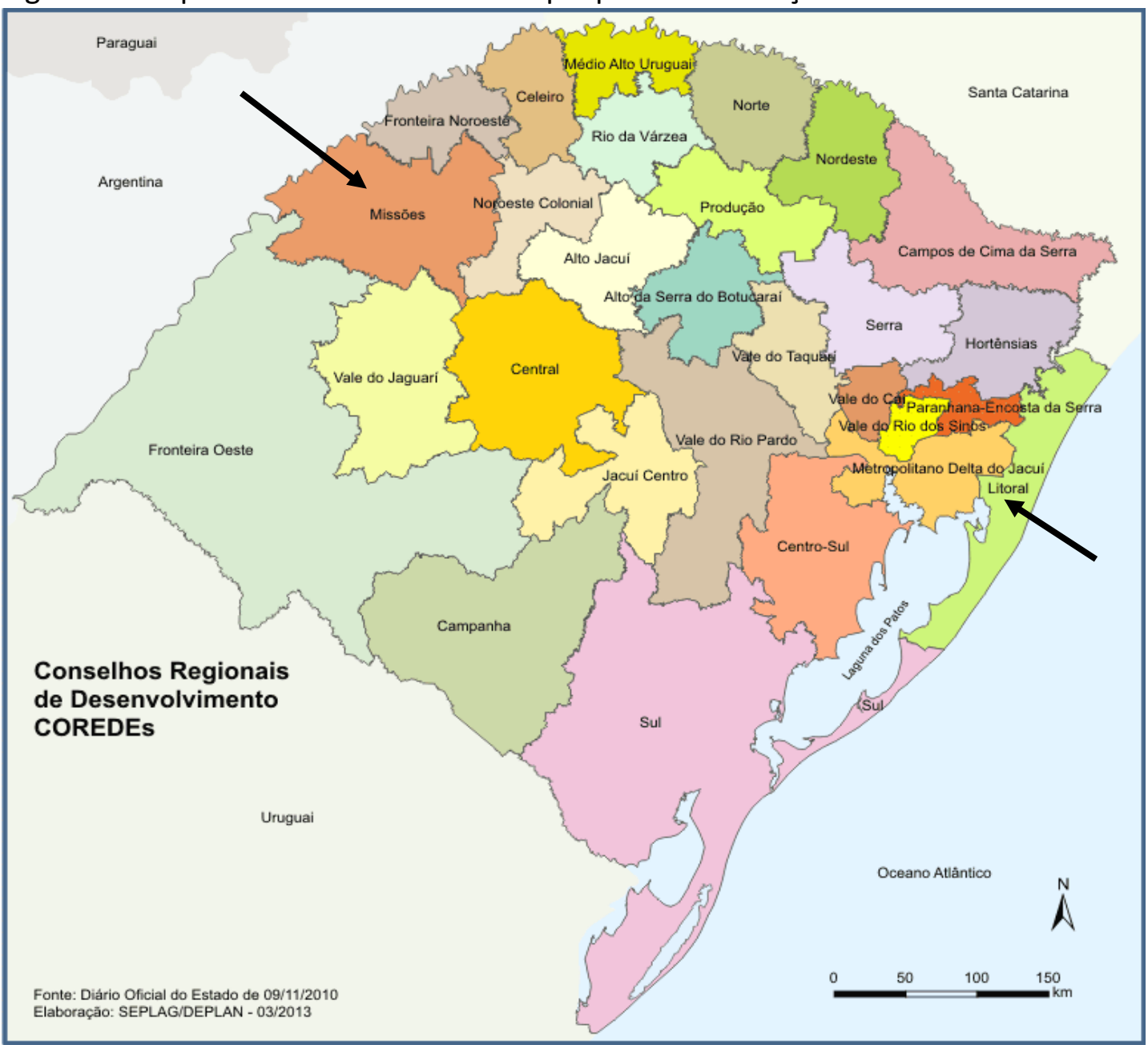

Fonte: Mapa extraído do Atlas socioeconômico do Rio Grande do Sul (2017) e adaptado pelos autores

Direcionando a análise para o acesso ao PRONAF, o estado do Rio Grande do Sul, no período de 2013-2018, acessou quase um milhão e meio de contratos, captando R\$ 32.771.706.766,72 (Tabela 2). Observa-se, de forma geral, que há um declínio no número de contratos para o período observado, cuja característica, no entanto, não é a mesma para os recursos captados, já que estes aumentaram no intervalo. Os dados mostram também que o valor médio dos contratos foi crescente no período investigado, apresentando no intervalo de seis anos mais que a duplicação do valor, ou seja, saltando de um valor médio de quase $\mathrm{R} \$ 15$ mil reais, para uma média de $\mathrm{R} \$ 31.540,08$, conforme pode ser observado na Tabela 2. 
Tabela 2 - Número de contratos e recursos acessados do PRONAF no RS (2013 - 2018)

\begin{tabular}{cccc}
\hline Ano & No de Contratos & Recursos Contratados (R\$) & Valor Médio dos Contratos (R\$) \\
\hline 2013 & 320.288 & $4.779 .131 .936,29$ & $14.921,36$ \\
2014 & 275.948 & $5.758 .095 .337,48$ & $20.866,60$ \\
2015 & 237.093 & $5.253 .635 .760,25$ & $22.158,54$ \\
2016 & 219.573 & $5.253 .998 .706,60$ & $23.928,25$ \\
2017 & 206.625 & $5.511 .114 .553,82$ & $26.672,06$ \\
2018 & 197.074 & $6.215 .730 .472,28$ & $31.540,08$ \\
\hline TOTAL & $\mathbf{1 . 4 5 6 . 6 0 1}$ & $\mathbf{3 2 . 7 7 1 . 7 0 6 . 7 6 6 , 7 2}$ & $\mathbf{2 2 . 4 9 8 , 7 5}$ \\
\hline
\end{tabular}

Fonte: Elaboração própria a partir de dados do Banco Central do Brasil (2019).

Entre os resultados encontrados, com relação ao total de contratos realizados no intervalo dos anos de 2013 e 2018, pelos Coredes Missões e Litoral, é possível observar a partir da Figura 02, que em ambas as regiões, houve uma redução no número total de contratos. Sendo que apenas nos anos de 2014 e 2018, as regiões em estudo, apresentam resultados dispares.

Figura 2: Gráfico com o Total de Contratos dos Coredes Missões e Litoral (2013-2018)

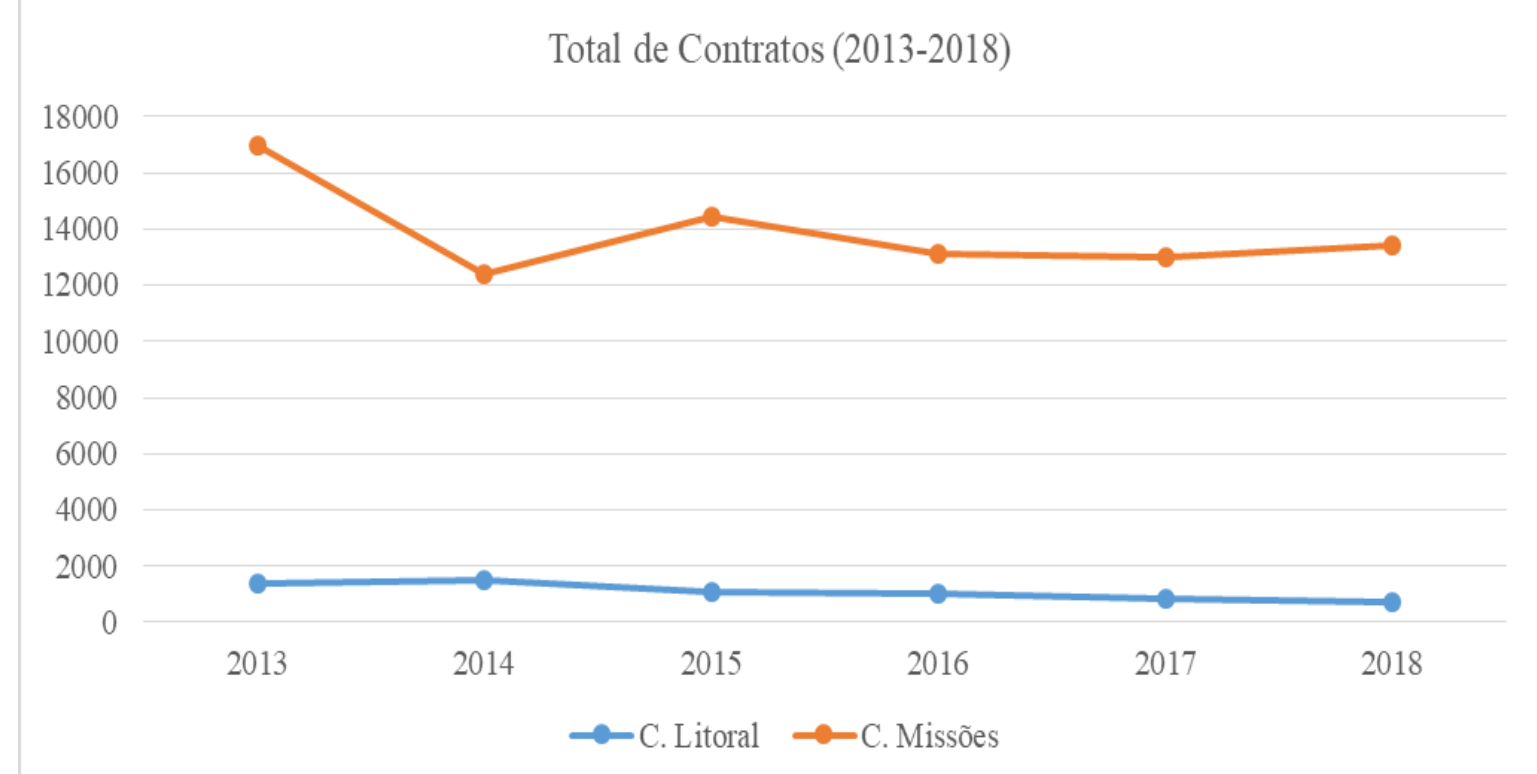

Fonte: Elaboração própria a partir de dados do Matriz de Dados do Crédito Rural do Banco Central do Brasil (2019).

Analisando o valor total de contratos dos Coredes, no intervalo dos anos de 2013 e 2018, percebe-se uma irregularidade significativa entre as regiões, sendo que no COREDE Missões verifica-se uma oscilação constante ao longo dos anos, ao passo que o COREDE Litoral apresenta uma linearidade maior, sem mudanças tão acentuadas, para os valores contratados, conforme demostrados na Figura 3. 
Figura 3 - Gráfico com o Valor Total de Contratos (R\$) dos Coredes Missões e Litoral (2013-2018) Total de Valores Contratados $(\mathrm{R} \$)$

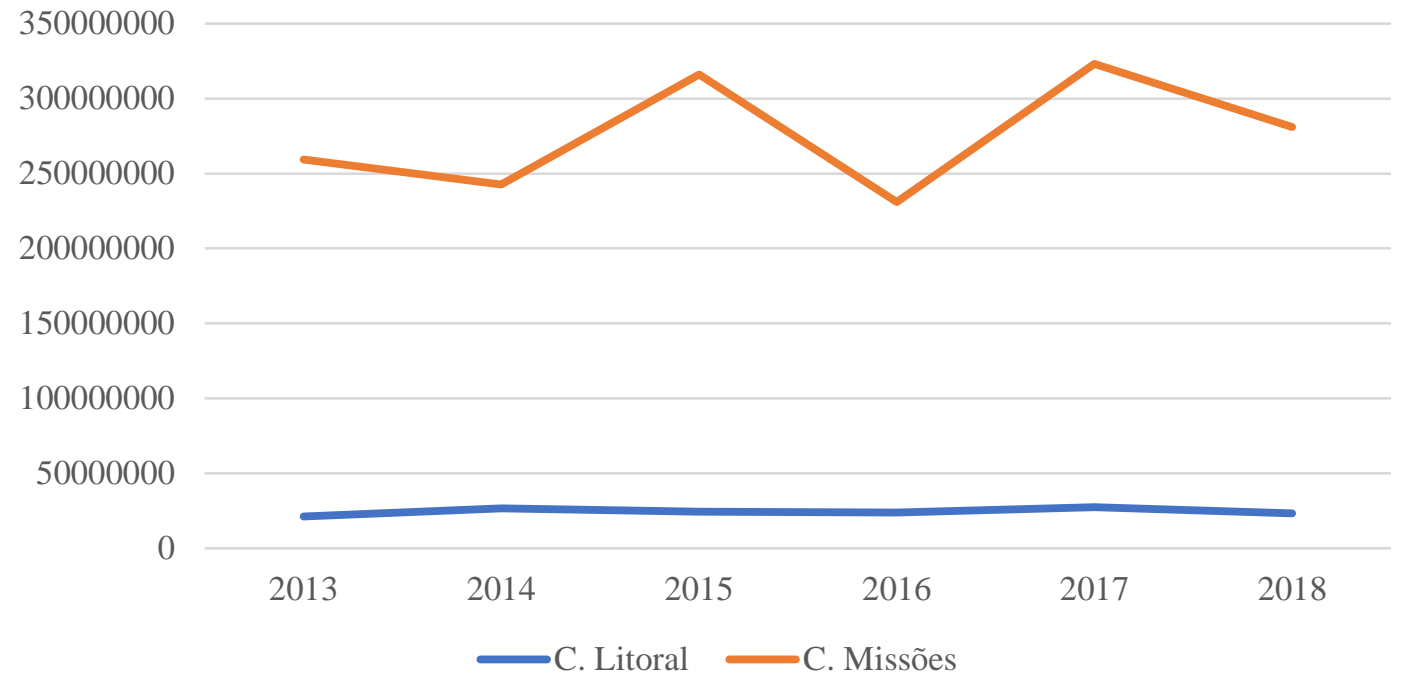

Fonte: Elaboração própria a partir de dados do Matriz de Dados do Crédito Rural do Banco Central do Brasil (2019).

Um olhar mais direcionado e individualizado, nos possibilita verificar que entre os municípios que compõe o COREDE Missões, somente no ano de 2018, sete municípios (Cerro Largo, Entre-ljuís, Giruá, Guarani das Missões, Roque Gonzales, Santo Ângelo, São Paulo das Missões) foram responsáveis por mais de $50 \%$ dos contratos, especificamente $52,62 \%$, de uma região composta por um total de 25 municípios, apontando assim para uma clara concentração (Tabela 3). 
Tabela 3 - Número de contratos do PRONAF por Municípios do COREDE Missões (2013 - 2018)

\begin{tabular}{|c|c|c|c|c|c|c|}
\hline Municípios & $\begin{array}{r}\text { contratos } \\
2013 \\
\end{array}$ & $\begin{array}{r}\text { contratos } \\
2014 \\
\end{array}$ & $\begin{array}{r}\text { contratos } \\
2015 \\
\end{array}$ & $\begin{array}{r}\text { contratos } \\
2016 \\
\end{array}$ & $\begin{array}{r}\text { contratos } \\
2017 \\
\end{array}$ & $\begin{array}{r}\text { contratos } \\
2018 \\
\end{array}$ \\
\hline Bossoroca & 378 & 269 & 249 & 260 & 255 & 310 \\
\hline Caibaté & 441 & 403 & 383 & 382 & 360 & 351 \\
\hline Cerro Largo & 1.089 & 991 & 891 & 851 & 818 & 809 \\
\hline Dezesseis de Novembro & 161 & 153 & 149 & 134 & 114 & 129 \\
\hline Entre-ijuís & 1.265 & 1.173 & 1.146 & 1.016 & 871 & 731 \\
\hline Eugênio de Castro & 566 & 498 & 445 & 434 & 384 & 381 \\
\hline Garruchos & 271 & 225 & 191 & 157 & 114 & 127 \\
\hline Giruá & 1.986 & 1.831 & 1.447 & 1.422 & 1.425 & 1.392 \\
\hline Guarani das Missões & 1.778 & 1.463 & 1.287 & 1.257 & 1.085 & 1.147 \\
\hline Mato Queimado & 432 & 427 & 399 & 393 & 378 & 373 \\
\hline Pirapó & 409 & 348 & 269 & 223 & 206 & 252 \\
\hline Porto Xavier & 779 & 710 & 605 & 588 & 589 & 573 \\
\hline Rolador & 457 & 323 & 310 & 292 & 303 & 329 \\
\hline Roque Gonzales & 946 & 826 & 822 & 807 & 801 & 809 \\
\hline Salvador das Missões & 525 & 493 & 475 & 449 & 465 & 433 \\
\hline Santo Ângelo & 1.872 & 1.586 & 1.417 & 1.351 & 1.257 & 1.267 \\
\hline Santo Antônio das Missões & 374 & 271 & 281 & 312 & 286 & 256 \\
\hline São Luiz Gonzaga & 532 & 401 & 354 & 328 & 324 & 413 \\
\hline São Miguel das Missões & 635 & 523 & 437 & 377 & 382 & 313 \\
\hline São Nicolau & 428 & 418 & 317 & 244 & 195 & 162 \\
\hline São Paulo das Missões & 1.364 & 1.153 & 1.041 & 1.011 & 974 & 925 \\
\hline São Pedro do Butiá & 501 & 487 & 456 & 484 & 467 & 465 \\
\hline Sete de Setembro & 702 & 585 & 569 & 521 & 428 & 439 \\
\hline Ubiretama & 945 & 877 & 824 & 766 & 677 & 671 \\
\hline Vitória das Missões & 651 & 605 & 503 & 450 & 550 & 389 \\
\hline TOTAL & 16970 & 12405 & 14443 & 13087 & 13013 & 13446 \\
\hline
\end{tabular}

Fonte: Elaboração própria a partir de dados do Banco Central do Brasil (2019).

Com relação aos valores médios dos contratos do PRONAF por municípios do COREDE Missões, municípios como Salvador das Missões e São Luiz Gonzaga se destacam, por durante o período analisado (2013-2018), sempre apresentarem, entre os municípios analisados, os valores mais elevados. Também, ao total são sete os municípios (Caibaté, Eugenio de Castro, Garruchos, Salvador das Missões, Santo Antônio das Missões, São Luiz Gonzaga, São Nicolau) que sempre tem superando a média regional dos valores dos contratos (Tabela 4). 
Tabela 4 - Valores Médios dos contratos do PRONAF por Municípios do COREDE Missões (2013 2018)

\begin{tabular}{|c|c|c|c|c|c|c|}
\hline Municípios & $\begin{array}{c}\text { Média } \\
\text { dos } \\
\text { contratos } \\
\text { (R\$) } 2013\end{array}$ & $\begin{array}{c}\text { Média dos } \\
\text { contratos (R\$) } \\
2014\end{array}$ & $\begin{array}{c}\text { Média } \\
\text { dos } \\
\text { contratos } \\
\text { (R\$) } 2015\end{array}$ & $\begin{array}{c}\begin{array}{c}\text { Média } \\
\text { dos }\end{array} \\
\text { contratos } \\
\text { (R\$) } 2016\end{array}$ & $\begin{array}{c}\text { Média } \\
\text { dos } \\
\text { contratos } \\
\text { (R\$) } 2017\end{array}$ & $\begin{array}{c}\text { Média } \\
\text { dos } \\
\text { contratos } \\
\text { (R\$) } 2018\end{array}$ \\
\hline Bossoroca & $13.337,22$ & $20.077,99$ & $19.992,85$ & $22.903,34$ & $24.575,25$ & $26.117,95$ \\
\hline Caibaté & $18.189,06$ & $23.166,89$ & $24.982,92$ & $29.114,86$ & $31.194,65$ & $36.656,14$ \\
\hline Cerro Largo & $11.584,84$ & $14.004,26$ & $14.844,60$ & $22.628,74$ & $20.503,70$ & $21.808,87$ \\
\hline Dezesseis de Novembro & $15.929,76$ & $21.060,12$ & $21.378,04$ & $19.282,09$ & $24.318,44$ & $26.349,20$ \\
\hline Entre-ijuís & $16.010,55$ & $21.120,95$ & $20.698,30$ & $24.733,22$ & $25.050,30$ & $29.873,91$ \\
\hline Eugênio de Cas & $17.148,64$ & $21.857,13$ & $25.767,08$ & $28.232,83$ & $30.448,36$ & $36.521,86$ \\
\hline Garruchos & $17.475,49$ & $28.361,12$ & $27.984,93$ & $31.882,91$ & $41.447,27$ & $41.229,27$ \\
\hline Giruá & $15.412,14$ & $20.039,55$ & $22.695,97$ & $25.227,10$ & $27.211,93$ & $30.504,88$ \\
\hline Guarani das Missões & $12.197,09$ & $15.613,85$ & $16.625,79$ & $18.940,68$ & $20.484,53$ & $24.820,39$ \\
\hline Mato Queimado & $17.061,17$ & & $18.274,20$ & $22.062,93$ & $22.427,33$ & $26.522,55$ \\
\hline Pirapó & $10.926,94$ & $19.017,74$ & $19.787,97$ & $23.481,88$ & $26.675,37$ & $29.508,39$ \\
\hline Porto Xavier & $6.551,35$ & $9.779,36$ & $13.040,50$ & $11.738,52$ & $16.118,21$ & $21.087,27$ \\
\hline Rolador & $13.435,83$ & & $22.467,97$ & $26.809,25$ & $29.673,26$ & $31.915,54$ \\
\hline Roque Gonzales & $11.667,15$ & $15.846,07$ & $15.944,86$ & $17.521,30$ & $19.402,23$ & $22.551,65$ \\
\hline Salvador das Missões & $22.123,09$ & $37.366,74$ & $41.374,49$ & $70.085,42$ & $39.771,32$ & $58.997,59$ \\
\hline Santo Ângelo & $14.812,15$ & $18.988,48$ & $20.396,53$ & $23.974,36$ & $25.911,73$ & $30.446,10$ \\
\hline Santo Antônio & $20.256,52$ & $30.790,37$ & $33.654,91$ & $61.295,74$ & $38.196,52$ & $44.370,78$ \\
\hline São Luiz Gonzaga & $35.195,18$ & $61.842,38$ & $57.903,56$ & $63.421,43$ & $64.091,11$ & $116.006,11$ \\
\hline São Miguel das Missões & $13.803,61$ & $21.139,34$ & $23.159,23$ & $26.508,47$ & $29.782,29$ & $34.621,27$ \\
\hline São Nicolau & $16.534,26$ & $23.216,41$ & $26.991,74$ & $31.815,35$ & $30.659,04$ & $35.665,18$ \\
\hline São Paulo das Missões & $9.505,97$ & $11.792,66$ & $13.184,47$ & $14.251,26$ & $17.240,37$ & $18.558,21$ \\
\hline São Pedro do Butiá & $12.305,03$ & $14.471,60$ & $16.099,16$ & $17.260,68$ & $21.026,29$ & $21.478,89$ \\
\hline Sete de Setembro & $13.216,62$ & $15.537,45$ & $17.923,62$ & $18.437,50$ & $21.057,58$ & $27.244,41$ \\
\hline Ubiretama & $10.175,90$ & $13.268,58$ & $12.741,75$ & $15.888,18$ & $16.596,86$ & $19.883,36$ \\
\hline Vitória das Missões & $13.311,91$ & $19.728,46$ & $21.745,96$ & $24.483,12$ & $20.407,52$ & $30.644,96$ \\
\hline MÉDIA & $14.241,81$ & $19.583,21$ & $20.710,89$ & $24.871,51$ & $24.983,39$ & $30.973,09$ \\
\hline
\end{tabular}

Fonte: Elaboração própria a partir de dados do Banco Central do Brasil (2019).

Segundo Haas (2008), o COREDE Missões é caracterizado por possuir uma base econômica mais voltada à agropecuária, com destaque para a criação de bovinos e suínos, além do cultivo da soja, do milho e do trigo, e, especificamente, para os estabelecimentos familiares se observa uma tendência geral de mudança da matriz produtiva, com gradativa diminuição ou abandono da soja e o investimento na diversificação produtiva, tendo a atividade leiteira como pilar de sustentação das unidades de produção. A partir de tais características, e os dados observados no presente trabalho, é possível identificar uma grande concentração em torno de alguns municípios, que vem acessando ao PRONAF e os respectivos, maiores valores do Programa, corroborando assim, para as análises realizadas a nível de país, que tem apontado para uma concentração cada vez maior dos recursos do Programa em torno de determinados Sistemas de Produção, conforme destacam Aquino; Gazolla e Schneider (2018, p. 138) "a política governamental de crédito rural que, em tese, deveria funcionar como um instrumento 
equalizador das desigualdades, parece estar desempenhando efeito contrário, ao aumentar e cristalizar a concentração produtiva no meio rural".

Diferentemente do COREDE Missões, o COREDE Litoral é caracterizado fundamentalmente pela procura do turismo de lazer, recebendo um fluxo intenso de veranistas, ou seja, nos referimos a uma região movida economicamente pelo turismo litorâneo de veraneio. No entanto, a região abriga também municípios essencialmente rurais, como é o caso de Caraá, Capivari do Sul, Dom Pedro de Alcântara, Itati, Mampituba, etc., e experiências bastante exitosas relacionadas ao rural, como é o caso da COOMAFITT - Cooperativa Mista de Agricultores Familiares de Itati, Terra de Areia e Três Forquilhas, e da primeira Denominação de Origem brasileira (DO): o Arroz do Litoral Norte Gaúcho, dentre outras.

Analisando os municípios que compõe o COREDE Litoral de forma individual é possível perceber que o número de contratos é relativamente baixo, tanto em relação ao COREDE Missões, como em relação ao total de contratos realizados pelo Estado, variando de 0,36\% em 2018 a 0,55\% em 2014 (Tabela 5).

Tabela 5 - Número de contratos do PRONAF por Municípios do COREDE Litoral (2013 - 2018)

\begin{tabular}{|c|c|c|c|c|c|c|}
\hline Municípios & 2013 & 2014 & 2015 & 2016 & 2017 & 2018 \\
\hline Arroio do Sal & 7 & 6 & 6 & 4 & 4 & 6 \\
\hline Balneário Pinhal & 7 & 2 & 1 & 1 & 3 & 0 \\
\hline Capão da Canoa & 9 & 4 & 2 & 0 & 4 & 6 \\
\hline Capivari do Sul & 15 & 16 & 10 & 6 & 6 & 5 \\
\hline Caraá & 121 & 107 & 112 & 95 & 83 & 72 \\
\hline Cidreira & 5 & 9 & 6 & 1 & 0 & 1 \\
\hline Dom Pedro de Alcântara & 62 & 59 & 36 & 40 & 38 & 31 \\
\hline Imbé & 31 & 19 & 1 & & 1 & 2 \\
\hline Itati & 32 & 30 & 19 & 18 & 20 & 23 \\
\hline Mampituba & 275 & 348 & 239 & 223 & 137 & 98 \\
\hline Maquiné & 115 & 165 & 107 & 85 & 64 & 42 \\
\hline Morrinhos do Sul & 130 & 142 & 79 & 89 & 63 & 67 \\
\hline Mostardas & 80 & 103 & 99 & 98 & 70 & 72 \\
\hline Osório & 32 & 26 & 19 & 14 & 16 & 13 \\
\hline Palmares do Sul & 69 & 55 & 35 & 27 & 26 & 29 \\
\hline Terra de Areia & 88 & 64 & 51 & 54 & 35 & 46 \\
\hline Torres & 90 & 110 & 69 & 83 & 115 & 81 \\
\hline Tramandaí & 11 & 19 & 13 & 9 & 12 & 11 \\
\hline Três Cachoeiras & 128 & 163 & 112 & 102 & 92 & 84 \\
\hline Três Forquilhas & 54 & 71 & 59 & 39 & 30 & 31 \\
\hline Xangri-lá & 1 & 4 & 4 & 4 & 0 & 0 \\
\hline TOTAL & 1362 & 1522 & 1079 & 992 & 819 & 720 \\
\hline
\end{tabular}

Fonte: Elaboração própria a partir de dados do Banco Central do Brasil (2019). 
Quando analisados separadamente, conforme Tabela 5, os dados referentes ao número de contratos por município, nota-se uma diminuição dos contratos, uma vez que no ano de 2013 o total de contratos no COREDE Litoral foi de 1362 e 720 no ano de 2018, ou seja, uma redução de quase $50 \%$ de 2013 a 2018.

Já quando se analisa a média dos valores contratados para o COREDE Litoral é possível identificar o movimento contrário, ou seja, um aumento de mais de 100\% no período de 2013 a 2018, dessa média, conforme demostrado na Tabela 6. Assim, quando confrontados os dados sobre o número de contratos e os valores, percebe-se que houve um aumento significativo na média de valor por contrato no decorrer dos anos analisados, uma vez que além do aumento do valor total acessado pela região, houve a diminuição dos contratos.

Tabela 6 - Valores Médios dos contratos do PRONAF por Municípios do COREDE Litoral (2013 2018)

\begin{tabular}{|c|c|c|c|c|c|c|}
\hline Municípios & $\begin{array}{l}\text { Média dos } \\
\text { contratos } \\
\text { (R\$) } 2013\end{array}$ & $\begin{array}{c}\text { Média dos } \\
\text { contratos (R\$) } \\
2014\end{array}$ & $\begin{array}{c}\text { Média dos } \\
\text { contratos (R\$) } \\
2015\end{array}$ & $\begin{array}{c}\text { Média dos } \\
\text { contratos (R\$) } \\
2016\end{array}$ & $\begin{array}{l}\text { Média dos } \\
\text { contratos } \\
\text { (R\$) } 2017\end{array}$ & $\begin{array}{c}\text { Média dos } \\
\text { contratos (R\$) } \\
2018\end{array}$ \\
\hline Arroio do Sal & $18.903,42$ & $14.664,37$ & $20.041,36$ & $64.098,14$ & $31.682,38$ & $54.299,96$ \\
\hline Balneário Pinhal & $3.959,35$ & $8.281,20$ & $39.355,00$ & $5.000,00$ & $3.049,13$ & 0,00 \\
\hline Capão da Canoa & $7.937,90$ & $12.960,32$ & $5.984,27$ & 0,00 & $32.994,74$ & $38.109,89$ \\
\hline Capivari do Sul & $21.596,16$ & $41.259,77$ & $33.294,59$ & $36.668,38$ & $44.542,32$ & $83.924,79$ \\
\hline Caraá & $7.007,22$ & $17.007,74$ & $12.223,81$ & $10.475,13$ & $20.809,59$ & $27.233,72$ \\
\hline Cidreira & $16.593,73$ & $12.022,81$ & $14.381,03$ & $92.088,85$ & 0,00 & $34.625,00$ \\
\hline $\begin{array}{l}\text { Dom Pedro de } \\
\text { Alcântara }\end{array}$ & $16.128,67$ & $24.977,46$ & $20.124,29$ & $22.615,99$ & $23.422,37$ & $27.329,00$ \\
\hline Imbé & $12.191,55$ & $16.680,84$ & $86.769,69$ & 0,00 & $4.798,00$ & $19.300,00$ \\
\hline Itati & $15.969,23$ & $35.759,05$ & $23.320,01$ & $29.468,10$ & $32.165,47$ & $37.198,71$ \\
\hline Mampituba & $16.839,85$ & $23.267,42$ & $21.611,81$ & $26.235,11$ & $26.439,01$ & $33.473,63$ \\
\hline Maquiné & $18.297,02$ & $30.576,46$ & $24.233,38$ & $28.193,04$ & $36.169,54$ & $30.951,00$ \\
\hline Morrinhos do Sul & $13.927,74$ & $20.292,27$ & $17.620,95$ & $23.191,00$ & $23.931,92$ & $29.742,00$ \\
\hline Mostardas & $10.364,01$ & $18.627,25$ & $19.217,18$ & $23.422,86$ & $33.683,94$ & $42.832,17$ \\
\hline Osório & $18.964,81$ & $30.940,68$ & $24.720,79$ & $21.820,93$ & $32.194,08$ & $41.941,02$ \\
\hline Palmares do Sul & $26.264,14$ & $39.169,19$ & $58.370,63$ & $69.043,70$ & $66.894,28$ & $68.694,11$ \\
\hline Terra de Areia & $14.923,29$ & $18.226,03$ & $31.426,42$ & $22.174,13$ & $21.020,58$ & $28.575,76$ \\
\hline Torres & $30.184,74$ & $34.425,36$ & $36.530,10$ & $44.437,23$ & $70.310,90$ & $45.808,98$ \\
\hline Tramandaí & $10.334,38$ & $16.680,84$ & $12.483,66$ & $13.792,13$ & $14.373,82$ & $14.728,06$ \\
\hline Três Cachoeiras & $13.310,30$ & $18.076,18$ & $17.452,08$ & $22.467,15$ & $19.952,74$ & $22.922,35$ \\
\hline Três Forquilhas & $14.777,18$ & $27.305,79$ & $23.643,14$ & $32.288,32$ & $25.304,83$ & $32.492,60$ \\
\hline Xangri-lá & $20.100,00$ & $17.986,99$ & $32.794,51$ & $23.023,00$ & 0,00 & 0,00 \\
\hline TOTAL & $16.031,19$ & $24.136,84$ & $22.748,82$ & $26.645,62$ & $33.511,79$ & $34.756,98$ \\
\hline
\end{tabular}

Fonte: Elaboração própria a partir de dados do Matriz de Dados do Crédito Rural do Banco Central do Brasil (2019). 
Ainda, em relação ao COREDE Litoral, de forma localizada, destaque-se quatro municípios, que em algum dos anos investigados não tiveram nenhum contrato, ou seja, não acessaram ao PRONAF, Balneário Pinhal, Cidreira, Imbé e Xangri-lá, este último não realizando contratos nos últimos dois anos, 2017 e 2018. Por outro lado, o município de Mampituba, no ano de 2018, foi responsável por $13,6 \%$ dos contratos da região.

Embora as regiões observadas no presente trabalho sejam claramente distintas, em ambas se percebe uma diminuição no número de famílias acessando recursos do PRONAF, e muitas vezes a resposta encontrada (HAAS, 2008; HAAS, BOLTER, CHAVES, 2019), é que isso ocorre pela burocracia excessiva, ou seja, necessidade de muitos documentos, muitos órgãos, necessidade de acesso a questões digitais, todas elas muito distantes do "mundo" dos agricultores, especialmente os familiares. Tal cenário, é propicio para o aparecimento dos intermediários, que oferecem crédito de forma direta, fazendo com que o agricultor se sinta valorizado em termos de princípios, mesmo que isso, por outro lado, lhe custe comprometimento com a compra de insumos determinados, ou em locais específicos, e/ou o comprometimento com a venda da produção em determinado local, ou para agentes específicos.

\section{Considerações finais}

O foco principal deste artigo consistiu em analisar, de forma conjunta, os resultados de duas regiões distintas do estado do Rio Grande do Sul, sobre o acesso a uma das principais políticas públicas de apoio à agricultura familiar, o PRONAF, tomando por base fundamentalmente o número de acessos e valores acessados. Para tanto, foi possível perceber que, de forma geral, a trajetória da política do crédito rural no Brasil, com a criação do sistema nacional de crédito, em 1965, possibilitou a agricultura brasileira acesso ao crédito de forma sequencial e institucionalizada.

Os resultados demonstram ainda que, os dados de acesso ao PRONAF pelo COREDE Missões e COREDE Litoral, comprovam a existência de uma concentração dos recursos nas mãos de um grupo cada vez menor de agricultores e municípios, indicando para uma especialização produtiva, com o desenvolvimento de restritas atividades agropecuárias.

Por fim, o estudo corroborou na constatação de que o crédito rural continua sendo um importante instrumento de estímulo e de fortalecimento da produção agrícola e, 
consequentemente, de incentivo ao aumento da produção, do emprego e da renda no meio rural. No entanto, particularmente, o PRONAF no estado do Rio Grande do Sul, a partir de algumas questões verificadas na pesquisa com os casos do COREDE Missões e COREDE Litoral, mais esta a favorecer a consolidação de um modelo de agricultura convencional centrado em determinados sistemas de produção, como grãos e leite, do que para a instauração de um modelo alternativo de desenvolvimento rural, pautado especialmente na maior autonomia com relação ao mercado.

Finaliza-se o presente trabalho, evidenciando que o PRONAF enquanto política de crédito rural, demonstra sérias dificuldades para atingir seu objetivo principal que seria o de gerar o fortalecimento da agricultura familiar.

\section{Referências}

ANJOS, F. S. GODOY, W. I. CALDA, N. V. e GOMES, M. C. Agricultura Familiar e Políticas Públicas: o Impacto do Pronaf no Rio Grande do Sul. In: Revista de Economia Rural. Rio de Janeiro, vol. 42, no 03, p. 529-548, jul/set 2004.

AQUINO, J. R. de; GAZOLLA, M.; SCHNEIDER, S.. Dualismo no Campo e Desigualdades Internas na Agricultura Familiar Brasileira. Revista de Economia e Sociologia Rural, Brasília, v. 56, n. 1, p. 123-142, mar. 2018.

AQUINO, J. R. de; SCHNEIDER, S.. O Pronaf e o desenvolvimento rural brasileiro: avanços, contradições e desafios para o futuro. In: GRISA, C.; SCHNEIDER, S. (Org). Políticas públicas de desenvolvimento rural no Brasil. Porto Alegre: Editora da UFRGS, 2015.

ASSIS, W. S. de. A construção da representação dos trabalhadores rurais no sudeste paraense. Tese (Instituto de Ciências Humanas e Sociais) - UFRJ. Rio de Janeiro. 2007.

ATLAS SOCIOECONÔMICO DO RIO GRANDE DO SUL. Disponível em:

$<$ http://www.atlassocioeconomico.rs.gov.br/conselhos-regionais-de-desenvolvimentocoredes $>$. Acesso em: 04 fev. 2019

BOLTER, J. A. G. Interfaces e cogestão nas políticas para agricultura familiar: uma análise do Programa Nacional de Habitação Rural. Tese (doutorado) - UFRGS, Porto Alegre - RS. 2013.

BCB. BANCO CENTRAL DO BRASIL. Sistema Financeiro Nacional: Crédito Rural. Sistema de Operações do Crédito Rural e do Proagro -SICOR. Matriz de Dados do Crédito Rural. 2019. Disponível em:

<http://www.bcb.gov.br/pt-br/\#!/c/MICRRURAL/>. Acesso em 6 fev. 2019.

CARNEIRO, M. J. Política pública e agricultura familiar: uma leitura do Pronaf. Estudos Sociedade e Agricultura, 8, abril 1997: 70-82.

FEE. Fundação Estadual de Economia e Estatística. Disponível em <www.fee.tche.br>. Acesso em fevereiro de 2019.

SECRETARIA DE GOVERNANÇA E GESTÃO ESTRATÉGICA. Planejamento Estratégico dos Coredes. Disponível em <https://governanca.rs.gov.br/planejamento-estrategico-dos-coredes>. Acesso em dezembro de 2020. 
GAZOLLA, M. Agricultura familiar, segurança alimentar e políticas públicas: uma análise a partir da produção para autoconsumo no território do Alto Uruguai/RS. Dissertação (mestrado) - UFRGS, Porto Alegre-RS. 2004.

GIMENES, R. M. T.; GIMENES, F. P.; GOZER, I. C.. Evolução do Crédito Rural no Brasil e o Papel das Cooperativas Agropecuárias no Financiamento dos Produtores Rurais. Anais. 46 Congresso da Sociedade Brasileira de Economia, Administração e Sociologia Rural (SOBER), Rio Branco, Acre, 2008.

GRAZIANO DA SILVA, J. A nova dinâmica da agricultura brasileira. Instituto de Economia, Unicamp. Campinas: Unicamp, 1998.

GRISA, C. Políticas públicas para a agricultura familiar no Brasil: produção e institucionalização das ideias. Tese (doutorado) - Universidade Federal Rural do Rio de Janeiro, Instituto de Ciências Humanas e Sociais, 2012.

GRISA, C., WESZ JR., V.J. e BUCHWEITZ, V.D. Revisitando o Pronaf: velhos questionamentos, novas interpretações. Revista de Economia e Sociologia Rural, v.52, n. 2, 2014.

HAAS, J. M. As diferenciações e transformações sócio-territoriais no espaço agrário das Missões/RS. Dissertação (Mestrado em Extensão Rural) - Universidade Federal de Santa Maria, Santa Maria, 2008.

HAAS, J. M.; BOLTER, J. A. G. e CHAVES, I. Y. Coredes Missões e Litoral: analisando dois contextos sob a influência de uma política de crédito rural. Anais 57을 Congresso da Sociedade Brasileira de Economia, Administração e Sociologia Rural, Ilhéus, 2019.

MATTEI, L. Impactos do PRONAF: análise de indicadores. Brasília: Ministério do Desenvolvimento Agrário. Núcleo de estudos agrários e Desenvolvimento Rural. Série Estudos NEAD: 11. 2005.

MATTEI, L. Políticas públicas de fomento à produção familiar no Brasil: O caso recente do PRONAF. Anais do XLIV Congresso da Sociedade Brasileira de Economia, Administração e Sociologia Rural (SOBER), Fortaleza, CE. 2006.

MÜLLER, Ana Luiza. A construção das políticas públicas para a agricultura familiar no Brasil: o caso do Programa de Aquisição de Alimentos. Dissertação (Programa de Pós-Graduação em Desenvolvimento Rural) - Faculdade de Ciências Econômicas, Universidade Federal do Rio Grande do Sul, Porto Alegre, 2007.

PRETTO, José Miguel. Amplitude e restrições ao acesso de Pronaf investimento no Rio Grande do Sul: um estudo de três operações de financiamento envolvendo cooperativas de crédito rural, cooperativas de produção agropecuária e o Banco Regional de Desenvolvimento do Extremo Sul. Dissertação (Mestrado em Desenvolvimento Rural) - Universidade Federal do Rio Grande do Sul, RS, 2005.

TAKAGI M. Câmaras Setoriais Agroindustriais, representação de interesses e políticas públicas. Rio de Janeiro: Annablume, 2004. 